\title{
THE SPECTRA OF BOUNDED LINEAR OPERATORS ON THE SEQUENCE SPACES ${ }^{1}$
}

\author{
CHARLES J. A. HALBERG, JR.
}

These remarks are the result of an investigation into the connections among the spectra of the various operators defined on the sequence spaces $l_{p}$ by the same infinite matrix.

We will have need of the following notation. Let $\left[l_{p}\right]$ denote the algebra of bounded linear operators mapping the sequence space $l_{p}$ into itself. If $A$ is an infinite matrix which defines an element of $\left[l_{p}\right]$ (we shall sometimes use the statement $A \in\left[l_{p}\right]$ to express this state of affairs), we shall denote that operator by $A_{p}$. We shall denote the transpose of the matrix $A$ by $A^{t}$. Let $\left\|A_{p}\right\|$ denote the norm of the operator $A_{p}$ on the sequence space $l_{p}$, and let $\sigma\left(A_{p}\right),\left|\sigma\left(A_{p}\right)\right|$ and $\rho\left(A_{p}\right)$ denote its spectrum, spectral radius and resolvent set respectively. If $T$ is the operator defined by the infinite matrix $\left(t_{i j}\right)$ we shall denote by $\bar{T}$ the operator defined by the infinite matrix $\left(\bar{t}_{i j}\right)$, where $\bar{z}$ denotes the complex conjugate of the complex number $z$. Similarly, if we have a vector $x=\left(\xi_{1}, \xi_{2}, \cdots\right)$, then $\bar{x}$ will denote the vector $\left(\bar{\xi}_{1}, \bar{\xi}_{2}, \ldots\right)$. The symbol $l_{p}(n)$ will denote the vector space of $n$ tuples of complex numbers, such that if $x=\left(\xi_{1}, \xi_{2}, \cdots, \xi_{n}\right) \in l_{p}(n)$, then $\|x\|_{p}=\left(\sum_{i=1}^{n}\left|\xi_{i}\right|^{p}\right)^{1 / p}$. Given a number $p, p^{\prime}$ will denote the number $p /(p-1)$ if $1<p<\infty$, and will denote $\infty$ or 1 respectively, according as $p=1$ or $p=\infty$. The statement " $q$ lies between $p$ and $p^{\prime}$ " will mean $p \leqq q \leqq p^{\prime}$ or $p^{\prime} \leqq q \leqq p$ respectively, according as $1 \leqq p \leqq 2$ or $2<p \leqq \infty$.

M. Riesz has proved that if $A$ is a matrix transformation of $l_{1 / \alpha}(n)$ into $l_{1 / \beta}(m)$ and $M_{\alpha \beta}$ is its norm, then $M_{\alpha \beta}$ as a function of the point $(\alpha, \beta)$ has the property that $\log \left(M_{\alpha \beta}\right)$ is a convex function in the triangle $0 \leqq \alpha \leqq 1,0 \leqq \beta \leqq 1, \alpha+\beta \leqq 1$, [2, pp. 466-471]. G. O. Thorin has shown that the theorem actually holds for the entire first quadrant of the $\alpha \beta$-plane, [4, pp. 5-6].

This result, with the use of a limiting process, implies the following inequality

$$
\left\|A_{1 / b}\right\|^{-c-a} \leqq\left\|A_{1 / a}\right\|{ }^{-b-b}\left\|A_{1 / c}\right\|^{b-a}
$$

Presented to the Society, November 12, 1955; received by the editors August 20, 1956.

1 The results of this paper are based in part on a University of California (at Los Angeles) thesis prepared under the direction of Professor Angus E. Taylor. 
where $0 \leqq a \leqq b \leqq c$. (It is understood that if $a=0,1 / a$ is replaced by $\infty$.) For the case where $1 \leqq p \leqq q \leqq r \leqq \infty$, this gives

$$
\left\|A_{q}\right\| \leqq\left\|A_{p}\right\|^{(r-q) p /(r-p) q}\left\|A_{r}\right\|^{(q-p) r /(r-p) q}
$$

it being understood that if $r=\infty$, then $(r-q) /(r-p)=r /(r-p)=1$. (For the case where $p=1, q=2$, and $r=\infty$, this is simply a reformulation of a theorem due to J. Schur [3, p. 6].) Or, since it can easily be shown that $\left\|A_{p^{\prime}}\right\|=\left\|\left(A^{t}\right)_{p}\right\|$, if we let $1 \leqq p \leqq \infty$ and let $q$ lie between $p$ and $p^{\prime}$ we can restate (2) as

$$
\left\|A_{q}\right\| \leqq\left\|A_{p}\right\|(p+q(1-p)) /(2-p) q\left\|\left(A^{t}\right)_{p}\right\|^{(q-p) /(2-p) q} .
$$

We note that (2) implies that if $1 \leqq p \leqq q \leqq r \leqq \infty$ and $A$ belongs to both $\left[l_{p}\right]$ and $\left[l_{r}\right]$, then $A \in\left[l_{q}\right]$ and that (3) implies that if $1 \leqq p \leqq \infty$, $q$ lies between $p$ and $p^{\prime}$, and both $A$ and $A^{t}$ belong to $\left[l_{p}\right]$, then $A \in\left[l_{q}\right]$.

Borrowing from the phraseology of M. Riesz, we state the following theorem.

Theorem 1. If $A \in\left[l_{1 / \alpha}\right]$ for each $\alpha, 0 \leqq \alpha \leqq 1$, then $\left|\sigma\left(A_{1 / \alpha}\right)\right|$ as a function of the number $\alpha$ has the property that $\log \left|\sigma\left(A_{1 / \alpha}\right)\right|$ is a convex function for $0 \leqq \alpha \leqq 1$.

Proof. We know that $\lim _{n \rightarrow \infty}\left\|\left(A_{1 / \alpha}\right)^{n}\right\| 1 / n=\left|\sigma\left(A_{1 / \alpha}\right)\right|$ provided $0 \leqq \alpha \leqq 1$, and (1) implies that

$$
\left\|\left(A_{1 / b}\right)^{n}\right\|(c-a) / n \leqq\left\|\left(A_{1 / a}\right)^{n}\right\|(c-b) / n\left\|\left(A_{1 / c}\right)^{n}\right\|(b-a) / n,
$$

for $0 \leqq a \leqq b \leqq c \leqq 1$. If we let $n$ approach infinity, we obtain

$$
\left|\sigma\left(A_{1 / b}\right)\right|^{c-a} \leqq\left|\sigma\left(A_{1 / a}\right)\right|^{c-b}\left|\sigma\left(A_{1 / c}\right)\right|^{b-a},
$$

which is the desired result.

When $1 \leqq p \leqq q \leqq r$ we can restate the inequality (4) as

$$
\left|\sigma\left(A_{q}\right)\right| \leqq\left|\sigma\left(A_{p}\right)\right|^{(r-q) p /(r-p) q}\left|\sigma\left(A_{r}\right)\right|^{(q-p) r /(r-p) q}
$$

provided $A$ belongs to both $\left[l_{p}\right]$ and $\left[l_{r}\right]$.

In the special case where $1 \leqq p \leqq \infty$ and $q$ lies between $p$ and $p^{\prime}$, we can use the well known fact that $\sigma\left(A_{p^{\prime}}\right)=\sigma\left(\left(A^{t}\right)_{p}\right)$ together with the inequality (5) to derive the following inequality, provided both $A$ and $A^{t}$ belong to $\left[l_{p}\right]$.

$$
\left|\sigma\left(A_{q}\right)\right| \leqq\left|\sigma\left(A_{p}\right)\right|^{(p+q(1-p)) /(2-p) q}\left|\sigma\left(\left(A^{t}\right)_{p}\right)\right|^{(q-p) /(2-p) q} .
$$

Using the inequality (5) we can immediately state the following theorem.

Theorem 2. Suppose that $T$ belongs to both $\left[l_{p}\right]$ and $\left[l_{r}\right]$, that 
$1 \leqq p \leqq q \leqq r \leqq \infty$ and that $\left|\sigma\left(T_{p}\right)\right| \neq\left|\sigma\left(T_{r}\right)\right|$. Then either

$$
\left|\sigma\left(T_{p}\right)\right|>\left|\sigma\left(T_{q}\right)\right| \text { or }\left|\sigma\left(T_{r}\right)\right|>\mid \sigma\left(T_{q}\right) \text { । }
$$

according as

$$
\left|\sigma\left(T_{p}\right)\right|>\left|\sigma\left(T_{r}\right)\right| \text { or }\left|\sigma\left(T_{r}\right)\right|>\left|\sigma\left(T_{p}\right)\right|,
$$

respectively.

The inequality (6) together with fact that if $q$ lies between $p$ and $p^{\prime}$, then so does $q^{\prime}$, and the fact that $\left|\sigma\left(A_{q^{\prime}}\right)\right|=\left|\sigma\left(\left(A^{t}\right)_{q}\right)\right|$ imply the following theorem.

TheOREM 3. Let both $T$ and $T^{t}$ belong to $\left[l_{p}\right], 1 \leqq p \leqq \infty$, let $q$ lie between $p$ and $p^{\prime}$ and let $\left|\sigma\left(T_{p}\right)\right| \neq\left|\sigma\left(\left(T^{t}\right)_{p}\right)\right|$. Then either

$$
\left|\sigma\left(T_{p}\right)\right|>\left|\sigma\left(T_{q}\right)\right| \text { or }\left|\sigma\left(\left(T^{t}\right)_{p}\right)\right|>\left|\sigma\left(\left(T^{t}\right)_{q}\right)\right|
$$

according as

$$
\left|\sigma\left(T_{p}\right)\right|>\left|\sigma\left(\left(T^{t}\right)_{p}\right)\right| \text { or }\left|\sigma\left(\left(T^{t}\right)_{p}\right)\right|>\left|\sigma\left(T_{p}\right)\right|,
$$

respectively.

We shall now use the inequalities (2) and (3) to derive some set relationships among the spectra of the operators defined on the sequence spaces $l_{p}$ by the same infinite matrix.

TheOREM 4. Let $T$ belong to both $\left[l_{p}\right]$ and $\left[l_{r}\right]$ and let $1 \leqq p \leqq q \leqq r \leqq \infty$. Then

$$
\sigma\left(T_{q}\right) \subset \sigma\left(T_{p}\right) \cup \sigma\left(T_{r}\right)
$$

and

(b) if $C$ is any component of $\sigma\left(T_{q}\right)$, then the set $C \cap\left(\sigma\left(T_{p}\right) \cap \sigma\left(T_{r}\right)\right)$ is nonvoid.

Proof. (a) Assume that $\lambda \in \rho\left(T_{p}\right) \cap \rho\left(T_{r}\right)$. This implies that $(\lambda I-T)^{-1}$ belongs to both $\left[l_{p}\right]$ and $\left[l_{r}\right]$. From (2) we infer that $(\lambda I-T)^{-1} \in\left[l_{q}\right]$, whence $\lambda \in \rho\left(T_{q}\right)$. We have thus proved that

$$
\rho\left(T_{p}\right) \cap \rho\left(T_{r}\right) \subset \rho\left(T_{q}\right),
$$

whence, by complementation, we have

$$
\sigma\left(T_{p}\right) \cup \sigma\left(T_{r}\right) \supset \sigma\left(T_{q}\right) .
$$

(b) Let us assume that $C \cap\left(\sigma\left(T_{p}\right) \cap \sigma\left(T_{r}\right)\right)$ is void. It is clear that $C \cap \sigma\left(T_{p}\right)$ and $C \cap \sigma\left(T_{r}\right)$ are both closed, and by our assumption they have no point in common; moreover, it can be shown that they are both nonvoid $[1$, p. 288]. But 


$$
C=\left(C \cap \sigma\left(T_{p}\right)\right) \cup\left(C \cap \sigma\left(T_{r}\right)\right)
$$

since, by (a), $\sigma\left(T_{q}\right) \subset \sigma\left(T_{p}\right) \cup \sigma\left(T_{r}\right)$. We are therefore forced to conclude that $C$ is not connected, which is in contradiction to our assumption that $C$ is a component.

We note that (b) implies, among other things, that $\sigma\left(T_{p}\right)$ and $\sigma\left(T_{r}\right)$ always have points in common.

Theorem 5. Suppose that both $T$ and $T^{t}$ belong to $\left[l_{p}\right], 1 \leqq p \leqq \infty$, and $q$ lies between $p$ and $p^{\prime}$. Then

$$
\begin{gathered}
\sigma\left(T_{q}\right) \subset \sigma\left(T_{p}\right) \cup \sigma\left(\left(T^{t}\right)_{p}\right), \\
\sigma\left(T_{2}\right) \subset \sigma\left(T_{q}\right) \cup \sigma\left(\left(T^{t}\right)_{q}\right) \subset \sigma\left(T_{p}\right) \cup \sigma\left(\left(T^{t}\right)_{p}\right),
\end{gathered}
$$

and

(c) if $C$ is any component of $\sigma\left(T_{q}\right)$, then the set

$$
C \cap\left(\sigma\left(T_{p}\right) \cap \sigma\left(\left(T^{t}\right)_{p}\right)\right)
$$

is nonvoid.

Proof. The statements (a) and (c) are proved in the same manner as statements (a) and (b) of Theorem 4 except that the inequality (3) is used instead of the inequality (2). The first containment of the statement (b) results from letting $q=2$ in (a), and the second containment results from (a) combined with the application of (a) to $T^{t}$.

Combining the result (b) of Theorem 5 with the classical result that the spectrum of a bounded operator defined on $l_{2}$ by a hermitian symmetric matrix is real, we obtain the following theorem.

Theorem 6. If $T \in\left[l_{p}\right], T=\bar{T}^{t}$ and $1 \leqq p \leqq \infty$ then

$$
\sigma\left(T_{2}\right) \subset \sigma\left(T_{p}\right) .
$$

Proof. Since if $x \in l_{p}, x \rightarrow \bar{x}$ gives an isometric isomorphic mapping of $l_{p}$ onto itself we see that if $T \in\left[l_{p}\right]$, then $\sigma\left(T_{p}\right)=\operatorname{Conj}\left[\sigma\left(\bar{T}_{p}\right)\right]$. Thus, since by hypothesis, $\left(T^{t}\right)_{p}=\bar{T}_{p}$, we have $\sigma\left(\left(T^{t}\right)_{p}\right)=\operatorname{Conj}\left[\sigma\left(T_{p}\right)\right]$ : whence result (b) of Theorem 5 implies that

$$
\sigma\left(T_{2}\right) \subset \sigma\left(T_{p}\right) \cup \operatorname{Conj}\left[\sigma\left(T_{p}\right)\right] .
$$

Knowing from a classical result that $T_{2}=\left(\bar{T}^{t}\right)_{2}$ implies that $\sigma\left(T_{2}\right)$ is real, we are led to the desired conclusion.

Our final theorem was suggested by Professor Angus E. Taylor.

Theorem 7. If $1 \leqq p \leqq q, T$ belongs to both $l_{p}$ and $l_{q}$, and $\lambda \in \rho\left(T_{q}\right)$, then a necessary and sufficient condition that $\lambda \in \rho\left(T_{p}\right)$ is that

$$
(\lambda I-T)\left(l_{q}-l_{p}\right) \subset l_{q}-l_{p} .
$$


Proof. Suppose that $\lambda \in \rho\left(T_{p}\right)$. Then $\lambda I-T$ maps $l_{p}$ onto $l_{p}$ in a 1-1 manner; and since by hypothesis $\lambda \in \rho\left(T_{q}\right), \lambda I-T$ maps $l_{q}$ onto $l_{q}$ in a 1-1 manner. Hence

$$
(\lambda I-T)\left(l_{q}-l_{p}\right)=l_{q}-l_{p} .
$$

Now suppose that $(\lambda I-T)\left(l_{q}-l_{p}\right) \subset l_{q}-l_{p}$. It follows that $(\lambda I-T)^{-1} l_{p} \supset l_{p}$, for if $x \in l_{p}$ and $(\lambda I-T) x=y$, then $y \in l_{p}$ and $(\lambda I-T)^{-1} y=x$, whence $x \in(\lambda I-T)^{-1} l_{p}$. If we now assume that $x \in\left((\lambda I-T)^{-1}\left(l_{p}\right)-l_{p}\right)$, then $x=(\lambda I-T)^{-1} y$, where $y \in l_{p}$ and $x \notin l_{p}$. But $(\lambda I-T) x=y$, which implies that $y \in l_{q}-l_{p}$ by our assumption that $(\lambda I-T)\left(l_{q}-l_{p}\right) \subset l_{q}-l_{p}$. This is a contradiction and we are thus led to the conclusion that $(\lambda I-T)^{-1}\left(l_{p}\right)-l_{p}$ is void, and this with our earlier conclusion implies that $l_{p}=(\lambda I-T)^{-1} l_{p}$. Thus we see that $(\lambda I-T)^{-1}$ (and hence also $\lambda I-T$ ) sets up a 1-1 map of $l_{p}$ onto $l_{p}$. From this it follows that $(\lambda I-T)^{-1}$ is bounded, for it is known that the inverse of a linear 1-1 map of a Banach space onto itself is bounded. The desired conclusion follows immediately.

\section{BIBLIOGRAPHY}

1. Charles J. A. Halberg, Jr. and Angus E. Taylor, On the spectra of linked operators, Pacific J. Math. vol. 6 (1956) pp. 283-290.

2. M. Riesz, Sur les maxima des formes bilinéaires et sur les fonctionnelles linéaires, Acta Math. vol. 49 (1926) pp. 465-497.

3. J. Schur, Bemerkungen zur Theorie der beschränkten Bilinearformen mit unendlich vielen Veränderlichen, J. Reine Angew. Math. vol. 140 (1911) pp. 1-28.

4. G. O. Thorin, Convexity theorems generalizing those of M. Riesz and Hadamard, with some applications, University of Lund thesis, Uppsala, 1948.

University of California, Los Angeles, and

University of California, Riverside 